\title{
Significado da intervenção médica e da fé religi osa para o paciente idoso com câncer
}

\author{
The meaning of medical intervention \\ and religious faith for the elderly cancer patient
}

Jorge Juarez Vieira Teixeira ${ }^{1}$

Fernando Lefèvre ${ }^{2}$

${ }^{1}$ Centro de Ciências M édicas eFarmacêuticas, Universidade Estadual do O estedo Paraná. Rua

Universitária 1619, Jardim Universitário. 85819-110

Cascavel PR.

jorgetei@hotmail.com

${ }^{2}$ Departamento dePrática

deSaúdePública, Faculdade deSaúdePública, USP.
Abstract This study aimed at identifying the meaning medical intervention and religious faith have for the elderly patient with cancer. A descriptive and qualitative investigation was developed between January 9 and M arch 28, 2001 in theH ospital do Servidor Público Estadual - Francisco M orato de Oliveira/IAM SPE (Hospital for State Public Servants). The studied sample was not randomized and consisted of 20 elderly men and women with cancer. The data were collected in semi-structured interviews and organized and analyzed using the Collective Subject Discourse method, applying three methodological illustrations: the Central Idea, Key Expressions and the Collective Subject Discourse (CSD). The main central ideas of the discourse material were: 1. Nothing to complain about. I think it is very good and they are on the right track; 2. No. For now, I'm doing everything the doctors say; 3. I've already participated, but not currently; 4. I don't participate in religious activity; 5. Invigoration, hope and balance. Religious faith is everything! 6. It remains the same; however, it changed the way to be. The CSD shows that the adopted medical intervention gave the elderly renewed hope and that religious faith is a key instrument for facing the disease.

Key words M edical intervention, Religiousfaith, Cancer, Elderly, Qualitative research
Resumo Neste estudo, procurou-se identificar o significado da intervenção médica e da féreligiosa para o paciente idoso com câncer. Pesquisa qualitativa e descritiva foi desenvolvida no período de 9/01 a 28/03/2001 no H ospital do Servidor Público Estadual - Francisco M orato de Oliveira/ IAM SPE. A amostra foi não aleatória, constituída de vinteidosos com câncer. A coleta de dados ocorreu mediante a técnica da entrevista semi-estruturada. Para a tabulação eanálise dos dados, utilizou-se o método do Discurso do Sujeito Coletivo, com aplicação detrêsfiguras metodológicas: a I déa Central, as Expressões-chave e o Discurso do Sujeito Coletivo (DSC). As principais idéias centrais presentes nos discursos foram: 1. Nada a reclamar. Eu acho muito bom e penso que eles estão no caminho certo; 2 . N ão. Por enquanto estou acompanhando tudo o que os médicosfalam; 3. Eu já participei, mas atualmente não; 4. Eu não participo de atividade religiosa; 5 . Fortal ecimento, esperança eequilíbrio. A féreligiosa étudo!; 6 . Continua a mesma, porém, mudou a maneira de ser. O DSC mostra que o procedimento médico adotado forneceu maior esperança ao paciente, elegendo a fé religiosa como instrumento-chave para o enfrentamento da doença.

Palavras-chave Intervenção médica, Fé religiosa, Câncer, Idoso, Pesquisa qualitativa 


\section{Introdução}

A aplicação de técnicas cirúrgicas, radioterápicas, quimioterápicas e biológicas para o tratamento resultam na cura de mais de $50 \%$ dos pacientes diagnosticados com câncer ${ }^{1}$. Ringdal ${ }^{2}$ re lata que, quando o diagnóstico ocorre precoce menteea intervenção éinstituída, o pacienteapre senta uma chance real de cura e o processo invasivo estará afastado. Paralelamente, se a força poderosa da mente for invocada e esta estiver aliada à fé religiosa, com o intuito de recuperarse do agravo, o paciente se sentirá mais feliz e com outra disposição para enfrentar a doença, podendo, desta forma, provocar alteração em seu quadro.

A religião, em sentido estrito senso, ocupa um importante espaço na vida das pessoas, e a religiosidade pode ajudá-las a encontrar o significado e a coerência no mundo ${ }^{3}$. Estudo realizado por $\mathrm{H}$ olland et al. ${ }^{4}$ sobre a função da religiosidadee da crença espiritual no enfrentamento do melanoma maligno destaca que a fé religiosa e a espiritualidade contribuíram de forma ativa na luta cognitiva dos pacientes e as suas convicções religiosas forneceram significado e perspectiva, permitindo acumular experiência para o enfrentamento da doença. Revisões sistemáticas têm confirmado quantitativamente que a religião é epidemiologicamente um fator de proteçãa ${ }^{5-7}$.

Apesar do avanço científico tanto curativo quanto preventivo do câncer, o câncer ainda leva consigo a idéia de sofrimento e morte ${ }^{8}$. Este fato, por si só, desencadeia reações emocionais peculiares que devem ser levadas em consideração $0^{9}$. As pessoas religiosas podem encontrar certo significado em situações ameaçadoras de vida e até em situações com resultados fatais prováveis². A religiosidade e a espiritualidade sempre foram consideradasimportantes aliadas das pessoas que sofrem e/ou estão doentes ${ }^{10}$.

Por que as pessoas procuram terapias complementares ou suplementares, incluindo a religião e a espiritualidade? Os pacientes em desespero podem ser desencorajados a respeito da realidade do tratamento convencional. Assim, o medo, os efeitos adversos, as experiências negativas anteriores e o desejo por mais cuidados de suporte são outras razões apresentadas pelo paciente para buscar a prática não convencional. As pessoas podem estar infelizes com a tecnologia impessoal da medicina moderna e, assim, procuram enfatizar o autocuidado e o bom estado do corpo, mente e espírito ${ }^{11}$.

A religião ea espiritualidade recentementetêm recebido atenção especial frente aos fatores psicossociais que podem influenciar os resultados da saúde física ${ }^{12}$. Para M itka ${ }^{13}$, finalmente os estudos estão emergindo e mostrando o benefício da religião e da espi ritualidade para a saúde pública. Levin ${ }^{7}$ relata que, sealgum dia a religião foi um tópico marginal das pesquisas em envelhecimento, atualmente não o é.

Os comportamentos religiosos são bastante freqüentes na idade avançada. Os profissionais da saúde que trabalham com estas pessoas devem estar alertas sobre a importância e a função da religião como visão demundo eestratégia para enfrentar o estresse ${ }^{14}$. Os idosos com câncer podem usar a sua religiosidade como uma estraté gia de enfrentamento na busca de alívio quando estão angustiados ${ }^{15}$.

Por que algumas pessoas idosas se tornam deprimidas, perdem a esperança e são incapazes de lutar eficazmente contra o câncer, enquanto outras com o mesmo agravo não se tornam deprimidas? Esta é uma área que deve ser explorada. A espiritual idade e a força que al guns idosos encontram ao expressar a sua fé religiosa podem explicar o porquê de eles não se deprimirem e serem capazes de manter a esperança, enfrentando eficazmente doen ças como o câncer ${ }^{15}$. A féem Deus cresce quando as pessoas ficam mais veIhas, aumentando, assim, a leitura da Bíblia e a participação em cultos ${ }^{16-19}$.

Esta investigação teve como objetivo identificar o significado da intervenção médica e da fé religiosa para o paciente idoso com câncer.

\section{Método}

A tipologia da pesquisa éde natureza qualitativa, descritiva. A amostra é não al eatória, composta por vinte pacientes idosos (60 anos ou mais) com câncer não hospitalizados. Os sujeitos da pesquisa foram atendidos na Central de Quimioterapia/Ambulatório de Oncologia e no Serviço de Assistência Domiciliar do Hospital do Servidor Público Estadual - Francisco M orato de Oliveira/IAM SPE. O estudo foi aprovado pelo comitê deética em pesquisa tanto da instituição promotora (FaculdadedeSaúdePública-USP) como da receptora (H ospital do Servidor Público Estadual - Francisco M orato de Oliveira/IAM SPE).

A coleta de dados ocorreu mediante a técnica da entrevista semi-estruturada, conformeformulário pré testado. As entrevistas foram desenvolvidas no período de 9 de janeiro a 28 de março de 2001. 
O critério de inclusão para a escolha dos pacientes foi estar ciente e informado de que era portador de câncer, independentemente da fase da doença quando da realização da quimioterapia. A Central deQuimioterapia, por intermédio do corpo de enfermagem, já sabedora da situação do paciente, perguntava ao mesmo se gostaria de conversar com o pesquisador e após confirmação positiva encaminhava-o. Além das informações da Central de Quimioterapia sobre a situação do paciente, o pesquisador também manteve contato com a equipemédica para confirmação dos fatos. N esse momento, em sala exclusiva, o pesquisador dialogava com o idoso para saber do interesse em participar da pesquisa. 0 critério de exclusão foi para os pacientes que aceitavam parcialmente a sua doença ou negavam o diagnóstico, fato esse informado previamente ao pesquisador pela Central de Quimioterapia. Um pacientefoi eliminado do estudo (não aceitação do diagnóstico) e um segundo negouse a participar por motivos pessoais.

A etapa seguinte consistiu na apresentação do objetivo e na pesquisa aos sujeitos eleitos. 0 termo de responsabilidade do pesquisador e de consentimento livre e esclarecido foi fornecido aos pacientes idosos com câncer e mais uma vez deixou-se livre a participação ou não do estudo. Aos candidatos que aceitaram garantiu-se total sigilo eanonimato. Os scritériosutilizados obedeceram à resolução 196/96 do Conselho Nacional de Saúde sobre pesquisas com seres humanos.

Para o tratamento dos dados foi empregada a técnica de análise do discurso do sujeito coleti$\mathrm{vo}^{20-23}$ queconsistenum conjunto de procedimentos de tabulação e organização de dados discursivos, sobretudo (mas não exclusivamente) daqueles provenientes de depoimentos orais.

Esses procedimentos envolvem, basicamente, as seguintes operações sobre os discursos coletados:

- Seleção das expressões-chave de cada discurso particular, por exemplo, de cada resposta a uma dada questão. As expressões-chave são segmentos contínuos ou descontínuos de discurso que revelam o principal do conteúdo discursivo; são uma espécie de "prova discursivo-empírica" da "verdade" das idéias centrais.

- Identificação da idéia central de cada uma dessas expressões-chave e queé a síntese do conteúdo dessas expressões, ou seja, o que elas querem efetivamente dizer. Identificação das idéias centrais semel hantes ou complementares.

- Reunião das expressões-chave referentes às idéias centrais semelhantes ou complementares, em um discurso síntesequeéo discurso do sujeito coletivo (DCS).

- O DCS representa, portanto, um expediente ou recurso metodológico destinado a tornar mais claras e expressivas as representações sociais, permitindo que um determinado grupo social (no caso de pacientes idosos) possa ser visto como autor e emissor de discursos comuns, compartiIhando entre seus membros. Com o sujeito coletivo, os discursos não se anulam ou se reduzem a uma categoria comum unificadora, já que o que se busca fazer é precisamente o inverso, ou seja, reconstruir, com pedaços de discursos individuais, como em um quebra-cabeça, tantos discursos-síntese quantos se julgue necessário para expressar uma dada "figura", um dado pensar ou uma representação social sobre um fenômeno.

A análise dos dados foi desenvolvida com suporte da literatura científica.

\section{Resultados ediscussão}

Os dados apresentados são referentes a vinte pacientes idosos com câncer. Não é pretensão exaurir a discussão dos DSC mas, sim, distinguir os pontos considerados de relevância em relação aos objetivos propostos.

Dos pacientes entrevistados, dez pertenciam ao sexo feminino e dez, ao masculino. A idade média foi de 67,1 anos para os homens e de 68,6 para as mulheres, com amplitude de 60 a 87 anos. Q uanto à escolaridade eestado civil, $55 \%$ possuíam oito anos ou mais de estudo e casado.

Conhecer a ótica do usuário que busca o serviço de saúde pública é uma etapa importante frente ao processo interventivo. Neste sentido, a primeira pergunta colocada para os sujeitos idosos tenta resgatar o pensamento sobre o tratamento médico frente ao seu problema de saúde. O Quadro 1 destaca três idéias centrais (IC) e respectivos discursos.

Primeira IC: "Nada a reclamar. Eu acho muito bom e penso que eles estão no caminho certo". No Discurso do Sujeito Coletivo (DSC), há destaque para um tratamento melhor e de que a internação hospitalar produziu bons frutos em seu estado de saúde. Um trecho do discurso chama a atenção para o resultado positivo dos recursos tecnológicos dispensados para o seu tratamento " $[. .$.$] com esse tratamento eu acho que$ eles estão no caminho certo [...] dentro do quea medicina dispõe [...]". 0 discurso também aparenta sinal de gratidão aos profissionais de saúde frente ao desempenho na situação problema. 
“Não tenho nenhuma queixa [...] não esperava melhor, porquesem o tratamento médico eu não estaria aqui".

Segunda IC: "Eu não tenho muita profundidade". Aqui a terapêutica frente à doença aparece no discurso coletivo como uma incógnita. Estudo longitudinal sobre o conhecimento dos pacientes com câncer avançado sobre o tratamento aponta que menos da metade dos 163 pacientes entendiam corretamenteo objetivo fundamental da terapia ${ }^{24}$.

Terceira IC: "Depende do procedimento mé dico". Para os pacientes desse discurso, o procedimento cirúrgico parece se apresentar de forma menos traumática. "A cirurgia quando erradica [...] eu acho que se torna mais fácil". Em sentido oposto, a quimioterapia ou a radioterapia emerge como terapêutica que podelevar ao desenvolvimento de eventos adversos: “[ ...] esse tratamento está muito agressivo ao corpo humano, né?".

$\mathrm{Na}$ vida de um paciente com câncer, a busca por terapias alternativas pode ocorrer com certa freqüência. Três IC possibilitaram a construção do material discursivo (Quadro 2).
PrimeiralC: "N ão. Por enquanto estou acompanhando tudo o que os médicos falam". 0 discurso coletivo para a maioria dos idosos (75\%) se apresenta deforma aderente ao procedimento médico acordado e as orientações parecem ser seguidas. Estudo realizado por Rodrigues et al..$^{25}$ com o objetivo de identificar al guns aspectos das crenças e dos sentimentos dos pacientes portadores de câncer sobre sua doença e tratamento evidenciou que a maioria dos pacientes (60\%) relatou que fazia somente o tratamento prescrito pelo médico e não utilizava outros tipos de tratamento.

Em contexto diferente, a afirmação " [...] a gente procura de tudo [...]" emerge na segunda IC. N este discurso, a fala do coletivo tendepara a busca de qualquer produto sugerido. É forte a procura pelo transcendental, benzimento, cura pelas mãos, etc, embora o tratamento oficial não deva ser abandonado. "[...] 0 tratamento oficial eu não aconselho deixar". Rosner ${ }^{11}$, em estudo sobrea religião ea medicina, afirma queo medo, os efeitos adversos, as experiências negativas pré vias e o desejo por mais cuidados de apoio são

Quadro 1. Idéia central e discurso do sujeito coletivo de vinte idosos com câncer. São Paulo, Brasil, 2001.

O que o(a) senhor(a) acha dos tratamentos médicos contra a sua doença?

Idéia Central (1)

Nada a reclamar. Eu acho muito bom e penso que eles estão no caminho certo.
Discurso do Sujeito Coletivo (1)

Eu acho muito bom. Aqui já tem um tratamento melhor e estou me sentindo bem. Eu estou achando importante. As primeiras quimio eu passei muito mal, vômito. Agora com esse tratamento eu acho que eles estão no caminho certo, fazendo o melhor pra gente. Eu não conseguia andar bem, sentar... fiquei aqui internado, tomando remédio e bem tratado. Eu acho que dentro do que a medicina dispõe, eles aplicaram em mim esses recursos. Não tenho nenhuma queixa, tive muito sucesso, está tudo sobre controle. Não esperava melhor, porque sem 0 tratamento médico eu não estaria aqui. Estou contente porque quero sair dessa. Agora estou sozinho e me sinto bem.

Idéia Central (2)

Eu não tenho muita profundidade.

Idéia Central (3) Depende do procedimento médico.
Discurso do Sujeito Coletivo (2)

Eu não tenho muita profundidade. Não sei se tem cura, não sei o sofrimento daqui pra frente, ou se regride a doença com esse tratamento, de maneira que eu não tenho assim, um prognóstico.

Discurso do Sujeito Coletivo (3)

A cirurgia quando erradica, há possibilidade de resolver o problema totalmente e a pessoa não precisa de tratamento quimioterápico e radioterápico, eu acho que se torna mais fácil... Agora, quando a pessoa precisa de quimioterapia, esse tratamento está muito agressivo ao corpo humano, né? Eu senti muito esse tratamento; tem diarréia, dor no reto, eu tive muito desconforto, isso mexe com o psiquismo da pessoa. 
algumas das razões apontadas por pacientes, justificando a busca por outras terapias. Estudo objetivando avaliar o uso de terapias complementares destaca queaproximadamente $33 \%$ dos pacientes idosos com câncer utilizam a terapia alternativa ${ }^{26}$. A urgência que muitos pacientes e familiares sentem em procurar qualquer beneficio em potencial ou uma opção de tratamento esperançoso leva muitos pacientes a tentar qualquer promessa de tratamento que é oferecido ${ }^{27}$.

Terceira IC: "Tudo! Mas agora apenas o tratamento médico". Há destaque para o caráter transitório. Num primeiro momento, a idéia central vem enaltecida pelo medo da perda da vida, porém as sugestões eram bem-vindas. "Tudo 0 que se possa imaginar [...]".

0 fato de já ter participado ou estar participando de alguma atividade religiosa foi a próxima indagação formulada aos idosos. 0 material coletado forneceu quatro IC (Q uadro 3).

Na primeira IC, "Sim, eu participo", o discurso mostra a importância das atividades religiosas. A participação do sujeito coletivo é pontuada em diversos movimentos. "Eu faço pregação de casa em casa, tenho também as reuniões [...] Já participei de diversas coisas [...]". Práticas religiosas podem ajudar o paciente a relaxar, distrair e a melhor aceitar os efeitos da solidão e do isolamento, situações tão freqüentes na fase idosa da vida28.
A segunda IC, "Eu já participei, mas atualmente não", realça o sujeito coletivo participativo em atividades religiosas no passado, mas no momento devido às limitações físicas, há impedimento para a sua atuação, embora a fé ainda esteja presente. "Agora eu não posso sair quase [...]". As pessoas idosas experienciam maiores limitações funcionais e neste sentido têm menor probabilidade de engajamento nas várias atividades da igreja, embora a atividade religiosa pessoal não cesse com 0 avançar da idade, há somente um desengajamento parcial das atividades religiosas organizadas ${ }^{29}, 30$.

Por outro lado, na terceira IC, aparece a expressão "Eu não participo de atividade religiosa". $\mathrm{Na}$ fala do coletivo transparece 0 não envolvimento em atividades religiosas, embora afirme que Deus ainda faz parte de sua vida. "Eu gosto de religião. Eventualmente eu recorro a um pensamento cristão".

Em contraste com a primeira ea segunda IC, porém, mais próximo da terceira IC, a quarta IC aparece com o tema "Na hora do aperto". Este discurso mostra um fato pitoresco que pode estar presentena vida deindivíduos que enfrentam situações de ameaça ou de rompimento com a vida, ou seja, a busca do transcendental quando os recursos terrestres findam. Pesquisa realizada sobre 0 apoio social baseado na igreja e no enfrentamento destaca que é mais provável que as

Quadro 2. Idéia central e discurso do sujeito coletivo de vinte idosos com câncer. São Paulo, Brasil, 2001.

O (a) senhor(a) já recorreu a outro tipo de tratamento para a sua doença?

I déia Central (1)

Não. Por enquanto estou acompanhando tudo o que os médicos falam.

I déia Central (2)

A gente procura de tudo.

Tudo! Mas agora apenas o

tratamento médico.
Discurso do Sujeito Coletivo (1)

$\mathrm{N}$ ão. Por enquanto estou acompanhando tudo o que os médicos falam e pela minha fé em Deus. Eu vou seguir as orientações. Não procurei nenhum outro alternativo. Somente o tratamento do hospital.

Discurso do Sujeito Coletivo (2)

Já. E a gente procura de tudo, né? Sempre pelo lado bom. Eu estou tomando ervas, ginseng, iodo, sal amargo, babosa, comprei comprimidos, não tem contra-indicações, não faz mal e está resolvendo... Eu estou me sentindo bem. Um padre benzeu, espiritualistas vieram aqui e fiz algumas sessões de cura pelas mãos. 0 tratamento oficial eu não aconselho deixar.

Discurso do Sujeito Coletivo (3)

Tudo! Tudo o que se possa imaginar. 0 que era me falado que dava certo eu ia. Fui e achei que não era o caminho que eu devia seguir. Apenas faço o meu tratamento médico. 
pessoas utilizem a questão religiosa como enfrentamento quando surgem tempos difícei ${ }^{31}$.

0 queaféreligiosa significa na vida do paciente idoso com câncer? Frente a esta questão, duas IC se apresentam (Quadro 4).

PrimeiralC: "fortal ecimento, esperança eequilíbrio. A féreligiosa étudo!". 0 discurso do sujeito evidencia uma ligação humana com Deus. "A religião éuma religação denós com o supremo". Estudo qualitativo sobre como as mulheres recém diagnosticadas com câncer de mama viviam destaca que uma parcela encontrou apoio em suas crenças religiosas e as crenças as capacitavam para continuar vivendo com a doença: "I believe there is something between heaven and earth, something that directs, and maybe that is the reason to keep holding on" ${ }^{32}$. Mull et al. ${ }^{33}$, em trabal ho sobre a função da religião na saúde e bem-estar de idosos, afirmam quea crença e as atividades religiosas foram importantes na vida de muitas idosas.

o discurso do sujeito coletivo destaca que quem tem féreligiosa se sente mais bem preparado e forte para lutar contra as adversidades da vida. "A fé religiosa faz com que a gente viva bem com a vida, sefortaleça etenhaum horizontemais santo". 0 sujeito coletivo também enaltece que somente a fé foi capaz de encorajá-lo a enfrentar várias intervenções cirúrgicas. Koenig ${ }^{34}$ relata que a crença e as práticas religiosas se tornam particularmente importantes para as pessoas quando setornam doentes e procuram enfrentar o estresse de um procedimento cirúrgico e a dificuldade do processo da reabilitação que algumas vezes se segue. Muitos pacientes vêem na féum "remédio" muito poderoso para o seu restabelecimento. Os pacientes com câncer mantêm a esperança por que buscam significado e confiança em um ser superior. A manutenção da esperança é importante para suportar o sofrimento ${ }^{35}$.

O postamente, a segunda IC, "Se eu não ver eu não acredito", parece apresentar o forte apelo do ver para crer. Para Krause et al. ${ }^{36}$, a dúvida religiosa ten dea desgastar os sentimentos debemestar psicológico.

A próxima questão buscou entender como era a fé religiosa antes da doença e como está agora. $\mathrm{Na}$ fala do sujeito coletivo, duas IC são destacadas (Quadro 5).

Quadro 3. I déia central e discurso do sujeito coletivo de vinte idosos com câncer. São Paulo, Brasil, 2001.

O (A) senhor (a) já participou ou participa de alguma atividade religiosa?

Idéia Central (1)

Sim, eu participo.

\begin{tabular}{l} 
\\
\hline $\begin{array}{l}\text { Idéia Central (2) } \\
\text { Eu já participei, mas } \\
\text { atualmente não. }\end{array}$ \\
\hline $\begin{array}{l}\text { Idéia Central (3) } \\
\text { Eu não participo de atividade } \\
\text { religiosa. }\end{array}$
\end{tabular}

religiosa.

Idéia Central (4)

Na hora do aperto.
Discurso do Sujeito Coletivo (1)

Sim. Eu tenho meu centro. Eu faço pregação de casa em casa, tenho também as reuniões. Eu sou de freqüentar missa aos domingos, assim por diante. Já participei de diversas coisas, membro de jovens com Cristo, grupo de oração né.

Discurso do Sujeito Coletivo (2)

Atualmente eu não estou participando de nenhuma, mas eu tenho a minha fé lá na igreja dos irmãos. Agora eu não posso sair quase, mas eu já participei. De um tempo pra cá, fui pensando primeiramente cuidar de mim, depois do próximo... Então a gente tem que estar bem com Deus, para poder cuidar do próximo. Está muito difícil pra mim ler letra miúda.

Discurso do Sujeito Coletivo (3)

$\mathrm{N}$ ão participo não. N ão faço parte de nenhuma comunidade. Eu não sou de freqüentar, não sou assíduo. Eu sou meio divorciado, mas eu sou católico, eu já fui à igreja, eu acredito em Deus. Eu gosto de religião. Eventualmente eu recorro a um pensamento cristão.

Discurso do Sujeito Coletivo (4)

Eu freqüento na hora do aperto. 
Primeira IC: "Continua a mesma, porém mudou a maneira de ser". Esta afirmação parece significar a busca de uma reflexão mais profunda na ótica do sujeito coletivo. "A minha manei ra de ser é muito diferente agora". Pessoas com forteféreligiosa podem redefinir eventos potencialmente negativos em sua vida em termos de reli- giosidade, como uma oportunidade de crescimento espiritual ou como parte de um plano divino mais amplo ${ }^{37}$.

Segunda IC: "Eu tinha muitas dúvidas. Agora eu estou mais segura". 0 discurso tende a revelar que a fé se fortaleceu após o sujeito passar por situações difíceis. "Depois queeu fiquei doen-

Quadro 4. Idéia central e discurso do sujeito coletivo de vinte idosos com câncer. São Paulo, Brasil, 2001.

\begin{tabular}{|l|l|}
\hline \multicolumn{2}{|l|}{ Qual o significado da fé religiosa para o(a) senhor(a)? } \\
\hline $\begin{array}{l}\text { I déia Central (1) } \\
\text { Fortalecimento, esperança e } \\
\text { equilíbrio. A fé religiosa é } \\
\text { tudo! }\end{array}$ & $\begin{array}{l}\text { Discurso do Sujeito Coletivo (1) } \\
\text { A religião é uma religação de nós com o alto, com o supremo. Quem tem } \\
\text { fé em Deus sempre consegue alguma coisa! Quem não tem fé, não } \\
\text { consegue nada. A fé religiosa faz com que a gente viva bem com a vida, } \\
\text { com o pessoal, se fortaleça, tenha esperança, confiança, equilíbrio, apego } \\
\text { e um horizonte mais santo. Sem ela eu não estaria viva, só a fé me fez } \\
\text { passar por quatro cirurgias em dois anos, quando todos achavam que eu } \\
\text { não saía do hospital. Eu tenho fé num Deus, em Jesus, alguns santos } \\
\text { também e eu peço que Deus dê proteção e saúde a todos aqueles que } \\
\text { estão em volta de mim. A religião é muito importante e eu sou muito } \\
\text { fervoroso. A gente precisa ter fé, força de vontade, nunca pode } \\
\text { desanimar, pois a fé deixa viver mais um pouco. Eu acho que a fé é tudo. }\end{array}$ \\
\hline Idéia Central (2) \\
Se eu não ver eu não acredito.
\end{tabular}

Quadro 5. Idéia central e discurso do sujeito coletivo de vinte idosos com câncer. São Paulo, Brasil, 2001.

\begin{tabular}{|l|l|}
\hline \multicolumn{2}{|l|}{ Como era a fé religiosa do(a) senhor(a) antes de ter a doença? E como é agora? } \\
\hline $\begin{array}{l}\text { I déia Central (1) } \\
\text { Continua a mesma, porém, } \\
\text { mudou a maneira de ser. }\end{array}$ & $\begin{array}{l}\text { Discurso do Sujeito Coletivo (1) } \\
\text { A mesma coisa. Não houve mudança. Eu acredito que Deus está me } \\
\text { ajudando. Eu sempre fui religiosa. Eu sempre tive uma fé em Deus muito } \\
\text { grande, uma esperança e fui aprendendo e crescendo e nunca mais eu } \\
\text { deixei. Eu nunca desviei os caminhos e nunca misturei religião com as } \\
\text { coisas materiais. Ela (a fé) em primeiro lugar, depois aqui ( o tratamento). } \\
\text { Claro que eu não poderia deixar um ou o outro. Um está muito } \\
\text { intrínseco com o outro. O que eu fazia antigamente eu faço a mesma } \\
\text { coisa, quem sabe até com um pouco mais de emoção, situação difícil... } \\
\text { pede mais ajuda... A minha maneira de ser é muito diferente agora. }\end{array}$ \\
\hline $\begin{array}{l}\text { Idéia Central (2) } \\
\text { Eu tinha muitas dúvidas. } \\
\text { Agora estou mais segura. }\end{array}$ & $\begin{array}{l}\text { Discurso do Sujeito Coletivo (2) } \\
\text { Antes de ter a doença eu vivia muito constrangida, não vivia bem, a } \\
\text { minha fé era bem fraca. Depois que eu fiquei doente, vim me operar, eu } \\
\text { acho que a minha fé cresceu... Mas, ainda tem de crescer mais. Antes eu } \\
\text { tinha uma fé em Deus, mas não conhecia, eu tinha muitas dúvidas. Hoje } \\
\text { é ao contrário, eu conheço muito bem a Bíblia, né, então a minha fé é } \\
\text { diferente. Agora, eu estou mais garantida, eu acredito que ter Deus... } \\
\text { resolve muito. Eu fui salvo, Deus, os médicos e minha família. }\end{array}$
\end{tabular}


te..., eu acho que a minha fé cresceu [...]".0 discurso coletivo deixa a entender que 0 aprofundamento da palavra sagrada forneceu maturidade ao idoso. É preciso acreditar, ter fé em algo transcendente que seja capaz de completar as ansiedades individuais e sociai $3^{38}$. Risberg et al. ${ }^{39}$, ao estudar a cura espiritual em 642 pacientes noruegueses hospitalizados com câncer num estudo multicentro, afirmam que 139 (23\%) relataram uma intensificação da fé religiosa depois do diagnóstico do câncer.

\section{Consi derações finais}

O discurso do sujeito coletivo idoso com câncer forneceu importante material para a análise e discussão. Quanto ao procedimento intervencionista, parece haver um sentimento de satisfação e de agradecimento aos profissionais de saúde envolvidos no tratamento e na aplicação dos recursos tecnológicos. 0 discurso mostra que 0 idoso tem pouco conhecimento das conseqüências da terapia intervencionista e de que o tempo poderá lhe fornecer maior entendimento. Também aparece 0 discurso de que quanto menos agressiva for à técnica instituída, melhor será para o bem-estar do paciente. A terapia alternativa na vida do paciente idoso com câncer se revela em várias nuances, ora inexistente, ora evidenciada, ora suprimida.

Quanto à féreligiosa, o discurso coletivo enaltece-a tendo como resultado a esperança, o equilíbrio e o fortalecimento, propiciando a luta pela vida e a serenidade para aceitar a doença. Para o sujeito coletivo, a fé e o tratamento aparecem como parceiros íntimos e a sinergia é positiva para o enfrentamento da doença. 0 discurso ainda mostra que 0 aprofundamento por meio da leitura de textos religiosos evidencia a maturidade, a segurança, o conforto e o otimismo em relação ao tratamento instituído.

\section{Colaboradores}

JJV Teixeira trabalhou na concepção teórica, pesquisa de campo, análise dos dados, elaboração e redação final do texto e $F$ Lefèvre participou na concepção teórica, análise dos dados e revisão do manuscrito.

\section{Agradecimentos}

Agradecemos a Fundação de Amparo à Pesquisa do Estado de São Paulo (FAPESP - Processo 98/ 15909-2) pelo apoio financeiro. 


\section{Referências}

1. Longo DL. Oncology and haematology. In: Braunwald $\mathrm{E}$, Fauci AS, Kasper DL, Hauser SL, Longo DL, Jameson JL, editors. Harrison's - Principles of internal medicine. New York: McGraw-Hill; 2001. p. 43-58.

2. Ringdal GI. Religiosity, quality of life, and survival in cancer patients. Soc Ind Res 1996; 38: 193-211.

3. Mickley JR, Soeken K, Belcher A. Spiritual well-being, religiousness and hope among women with breast cancer. Image - J N urs Scholarsh 1992; 24(4):267-272.

4. Holland JC. The roles of religious and spiritual beliefs in coping with malignant melanoma. Psycho-Oncology 1990; 8(1):14-26.

5. Larson DB, Pattison EM, Blazer DG, Omran AR, Kaplan BH. Systematic analysis of research on religious variables in four major psychiatric journals, 1978-1982. Am J Psychiatry 1986; 143(3):329-334.

6. Kark JD, Shemi G, Friedlander Y, Martin O, Manor $\mathrm{O}$, Blondheim SH. Does religious observance promote health? M ortality in secular vs religious kibbutzim in Israel. Am J Public Health 1996; 86(3):341-346

7. Levin JS. Religious research in gerontology, 19801994: a systematic review. J Rel Gerontolol 1997; 10(3):3-31.

8. Cyrillo PI, Pazzoto M. O papel do psicólogo no tratamento oncológico. In: Baracat FF, Fernandes JrHJ, Silva MJ, organizadores. Cancerologia atual. Um enfoque multidisciplinar. São Paulo: Roca; 2000. p. 173-185.

9. Carvalho VA. Psicoterapia em oncologia. In: MM Brentani, FRG Coelho, H Iyeyasu, LP Kowalski, organizadores. Bases da Oncologia. São Paulo: Lemar; 1998. p. 607-632.

10. Fleck MPAB, Newlands Z, Bolognesi G, Rocha NS Desenvolvimento do WHOQOL, módulo espiritualidade, religiosidade e crenças pessoais. Rev Saúde Pública 2003; 37(4):446-455.

11. Rosner F. Religion and M edicine. Arch Intern M ed 2001; 165(15):1811-1822.

12. Chen YY, Koenig HG. Do people turn to religion in times of stress? An examination of change in religiousness among elderly, medically ill patients. J Nerv M ent Dis 2006; 194(2): 114-120.

13. Mitka $M$. Getting religion seen as help in being well. JAM A 1998; 280(22):1896-1897.

14. Lotufo-Neto F. Psiquiatria e religião - a prevalência de transtornos mentais entre ministros religiosos [tese]. São Paulo (SP): Faculdade de M edicina, Universidade de São Paulo; 1997.

15. Fehring RJ, Miller JF, Shaw C. Spiritual well-being, religiosity, hope, depression, and other mood states in elderly people coping with cancer. Oncol Nurs Forum 1997; 24(4):663-671.

16. Blazer D, Palmore E. Religion and aging in a longitudinal panel. Gerontologist 1976; 16(1 Pt1): 82-85.

17. Young G, Dowling W. Dimensions of religiosity in old age: accounting for variation in types of participation. J Gerontol 1987; 42(4):376-380.
18. Marwick C. Should physicians prescribe prayer for health? Spiritual aspects of well-being considered. JAM A 1995; 273(20):1561-1562.

19. Koenig HG. The healing power of faith. Ann Long Term Care 1999; 7(10):381-384.

20. Lefèvre $F$, Lefèvre $A M C$. Os novos instrumentos no contexto da pesquisa qualitativa. In: Lefèvre $F$, Lefèvre AM C, Teixeira JJV, organizadores. 0 discurso do sujeito coletivo: uma nova abordagem metodológica em pesquisa qualitativa. Caxias do Sul: EDUCS; 2000. p. 11-35.

21. Lefèvre F, Teixeira JJV, Lefèvre AM C, Castro LLC, Spínola AWP. The Qualitative Report [serial online] 2004 dec [cited 2006 jun 5]: 9(4). Available from: http://www.nova.edu/ssss/QR/QR9-4/lefevre. pdf.

22. Lefèvre $F$, Teixeira JJV. A prescrição medicamentosa sob a ótica do paciente idoso. Rev. Saúde Pública 2001; 35:207-213.

23. Lefèvre $F$, Lefèvre $A M C$. $O$ discurso do sujeito coletivo. Um novo enfoque em pesquisa qualitativa. Caxias do Sul: EDUCS; 2003.

24. Craft PS, Burns CM, Smith WT, Broom DH. Knowledge of treatment intent among patients with advanced cancer: a longitudinal study. Eur J Cancer Care 2005; 14(5):417-425.

25. Rodrigues C, Kajiya M, Gazzi O. O paciente com câncer: crenças e sentimentos sobre sua doença e 0 tratamento. Acta Oncol Brás 1991; 11(1,2,3):123-126.

26. Wyatt GK, Friedman LL, Given CW, Given BA, Beckrow KC. Complementary therapy use among older cancer. Cancer Pract 1999; 7(3):136-144.

27. Massie MJ, Chertkov L, Toth AJ. Psychological issues. In: JrVT Devita, S Hellman,SA Rosenberg, editors. Cancer - principles e practice of oncology. Philadelphia: Lippincott Williams \& Wilkins; 2001. p. 3058-3065.

28. Koenig HG, George LK, Titus P. Religion, spirituality, and health in medically ill hospitalized older patients. J Am Geriatr Soc 2004; 52(4):554-562.

29. Ainlay SC, Smith DR. Aging and religious participation. J Gerontol 1984; 39(3):357-363.

30. Ainlay SC, Singleton JrR, Swigert VL. Aging and religious participation: reconsidering the effects of health. J Science Study Rel 1992; 31(2):175-182.

31. Krause N, Shaw BA, Marcum JP, Boardman JD. Church-based social support and religious coping. J Science Study Rel 2001; 40(4):637-656.

32. Landmark BT, Strandmark M, Wahl AK. Living with newly diagnosed breast cancer - the meaning of existential issues. Cancer Nurs 2001; 24(3):220-226.

33. Mull CS, Cox CL, Sullivan JA. Religion's role in the health and well-being of well elders. Public $\mathrm{H}$ ealth Nurs 1987; 4(3):151-159.

34. Koenig HG. Spiritual aspects of surgery. O phthalmol Clin North Am 2000; 13(1):71-83. 
35. Duggleby W. Enduring suffering: a grounded theory analysis of the pain experience of elderly hospice patients with cancer. Oncol N urs Forum 2000; 27(5):825-831.

36. Krause N, Ingersoll-Dayton B, Ellison CG, Wulff $\mathrm{KM}$. Aging, religious doubt, and psychological wellbeing. Gerontologist 1999; 39(5):525-533.

37. Ellison CG. Religious involvementt and subjective well-being. J Health Soc Behav 1991; 32(1):80-99.

38. Bassini PF. Dimensão espiritual e a terceira idade. In: Duarte YAO, Diogo MJD'E, organizadores. Atendimento domiciliar: um enfoque gerontológico. São Paulo: Atheneu; 2000. p. 487-98.

39. Risberg T, Wist E, Kaasa S, Lund E, Norum J. Spiritual healing among Norwegian hospitalised cancer patients and patients' religious needs and preferences of pastoral services. Eur J Cancer 1996; 32A(2):274281.

Artigo apresentado em 12/07/2006

Aprovado em 25/06/2007

Versão final apresentada em 10/07/2007 